\title{
Nicotinic Receptors of Frog Ganglia Resemble Pharmacologically Those of Skeletal Muscle
}

\author{
Diane Lipscombe and Humphrey P. Ranga \\ M.R.C. Receptor Mechanisms Research Group, Department of Pharmacology, University College London, London WC1E \\ 6BT, United Kingdom
}

The actions of ACh antagonists were studied on synaptic currents of autonomic ganglia of the frog. Fast excitatory synaptic currents (ESCs) were recorded from cardiac and paravertebral neurons with the use of the 2-microelectrode voltage-clamp method. The actions of $4 \mathrm{ACh}$ antagonists, tubocurarine, hexamethonium, trimetaphan, and decamethonium were studied. Tubocurarine was effective at reducing the peak amplitude of ESCs (50\% inhibition at $3 \mu \mathrm{M})$. In contrast, tubocurarine $(1-30 \mu \mathrm{m})$ reduced the time constant of ESC decay by only $9 \%$ compared with controls. Both of these effects of tubocurarine were independent of membrane potential. Hexamethonium was a weak inhibitor of ESCs; at $600 \mu \mathrm{M}$ peak amplitude was reduced only to about $60 \%$ of controls and decay time constants were unaffected at concentrations between 10 and $600 \mu \mathrm{M}$. These effects of tubocurarine and hexamethonium are consistent with these drugs being receptor antagonists with no evidence of ion channel block. Trimetaphan (3-100 $\mu \mathrm{M})$ and decamethonium $(100 \mu \mathrm{M})$ reduced the peak amplitude of ESCs. In the presence of $100 \mu \mathrm{M}$ trimetaphan or $10 \mu \mathrm{M}$ decamethonium, ESC decays were biexponential. The 2 exponential components induced by the presence of these drugs were faster and slower, respectively, than the single-exponential component of control ESC decays. The effects of these 2 drugs were more pronounced at hyperpolarized potentials and are consistent with a channel-blocking action. The actions of the 4 ACh antagonists on frog autonomic ganglia are similar to their effects at the neuromuscular junction but dissimilar to their effects on the rat submandibular ganglion. We conclude that the $\mathrm{ACh}$ receptor-ion channel complex present on ganglia on the frog is pharmacologically similar to that at the end-plate and represents a distinct class of neuronal nicotinic receptor responsible for mediating fast excitatory transmission.

The nicotinic ACh receptor found on mammalian neurons is clearly distinct, both pharmacologically and kinetically, from the nicotinic receptor of skeletal muscle (see Colquhoun, 1981). The nicotinic receptor of neurons differs from that of muscle in

\footnotetext{
Received July 20, 1987; revised Dec. 10, 1987; accepted Feb. 8, 1988.

We thank the M.R.C. for providing the financial support for this study. We are most grateful to David Colquhoun for critical reading of the manuscript.

Correspondence should be addressed to Diane Lipscombe, Ph.D., Yale University, Department of Cellular and Molecular Physiology, School of Medicine, 333 Cedar Street, New Haven, CT 06510.

a Present address: Sandoz Institute London, Gower Place, London WClE 6BT U.K

Copyright @ 1988 Society for Neuroscience $0270-6474 / 88 / 093258-08 \$ 02.00 / 0$
}

the amino acid sequences of their $\alpha$-subunits (Boulter et al., $1986)$ and, more generally, their different sensitivities to various $\mathrm{ACh}$ antagonists. For example, $\alpha$-bungarotoxin $(\alpha-\mathrm{BuTx})$ is an irreversible inhibitor of synaptic transmission at the neuromuscular junction (Miledi and Potter, 1971), whereas it is without effect in several ganglion preparations, including the rat superior cervical ganglion (Brown and Fumagalli, 1977), guinea pig myenteric plexus (Bursztajn and Gershon, 1977), and rat submandibular ganglion (Ascher et al., 1979). Neuronal and muscle ACh receptor-channel complexes also differ in their sensitivity to ion channel block. Hexamethonium blocks synaptic transmission in the superior cervical ganglion of the cat (Paton and Zaimis, 1951; Lee and Nishi, 1972) and submandibular ganglion of the rat (Rang, 1982) but has little effect on transmission at the neuromuscular junction (Milne and Byrne, 1981). Ion channel block is the main mechanism by which hexamethonium, and certain other drugs, blocks transmission in the rat submandibular ganglion (Aschcr et al., 1979; Rang, 1982; Gurney and Rang, 1984) and rabbit sympathetic ganglia (Skok et al., 1983; Skok, 1986), whereas at the end-plate receptor antagonism is, in general, a more prominent mechanism of inhibition.

There is also good evidence that more than one type of neuronal nicotinic receptor exists. $\alpha$-BuTx has been found to block cholinergic transmission at certain vertebrate synapses such as the retinotectal synapse of the toad (Freeman, 1977) and goldfish (Freeman et al., 1980), in the chick ciliary ganglion (Chiappinelli and Zigmond, 1978; Ravdin and Berg, 1979), and in sympathetic ganglia of the bullfrog (Marshall, 1981). Diversity in the neuronal nicotinic receptor is also implied by the isolation of distinct cDNA clones encoding different $\alpha$-subunits in various regions of the mammalian brain (see Goldman et al., 1987).

We were interested to determine whether the ability of $\alpha$-BuTx to block synaptic responses in certain ganglia might be due to the presence of a class of nicotinic receptor different from that mediating fast excitatory transmission in mammalian ganglia. Others have suggested that the ability of $\alpha$-BuTx to block synaptic transmission in some ganglia may depend on the undetected presence of different amounts of 2 other $\alpha$-toxins, referred to as fractions 3.1 and 3.3, which appear to be more effective inhibitors of synaptic transmission in chick ciliary ganglia than $\alpha$-BuTx (Ravdin and Berg, 1979). $\alpha$-Toxins from fraction 3 can also inhibit synaptic transmission at the neuromuscular junction (Lee et al., 1972).

We chose to characterize the action of certain ACh antagonists, already extensively studied in mammalian ganglia (rat submandibular: Ascher et al., 1979; Rang, 1982; Gurney and Rang, 1984; rabbit sympathetic: Skok et al., 1983; Skok, 1986), in frog ganglia, which from studies with $\alpha$-BuTx were likely to 
have a different type of neuronal nicotinic receptor. We show that the actions of $\mathrm{ACh}$ antagonists on synaptic currents recorded from frog ganglia are indeed different from their actions previously reported on mammalian ganglia, and more similar to their actions at the neuromuscular junction.

A preliminary account of this work has been published in abstract form (Lipscombe and Rang, 1984).

\section{Materials and Methods}

Preparation and recording. Cardiac and paravertebral ganglia were removed from frogs (Rana pipiens) and prepared for intracellular recording as described by others (sympathetic: Nishi and Koketsu, 1960; cardiac: McMahan and Kuffler, 1971). Ganglia were pinned to a Sylgard resin-coated recording chamber. Preganglionic stimulation was achieved via a suction electrode into which the vagosympathetic nerve branches of the cardiac ganglion - or in the case of the sympathetic ganglia, the paravertebral chain above ganglion 7-were secured. Only B-type neurons are excited by stimulating the chain anterior to the seventh ganglion (Skok, 1965; Libet et al., 1968). Individual neurons were identified with a Nomarski optical system and $\mathrm{a} \times 40$ water-immersion objective. Recording methods were essentially the same as those described by Ascher et al. (1979) and Rang (1981). Nerve-evoked synaptic currents were elicited by suprathreshold stimuli between 0.2 and $0.5 \mathrm{msec}$ in duration delivered from a Grass stimulator (S44) and isolation unit. Synaptic currents were recorded from individual neurons with the use of the 2-microelectrode voltage-clamp method. Electrodes (40-60 M $\Omega$ ) were filled with $4 \mathrm{M}$ potassium acetate solution for voltage recording and 0.5 $M$ potassium sulfate solution for current injection. After impalement with 2 electrodes, neurons were held under voltage clamp at a potential close to the resting potential, generally between -40 and $-80 \mathrm{mV}$. When necessary, the voltage was stepped to the required potential (usually between -30 and $-100 \mathrm{mV}$ ) for about $500 \mathrm{msec}$, prior to preganglionic stimulation. The frequency response of the voltage clamp was optimized for each cell by adjusting the clamp gain and the negative capacitance feedback to the input stage. A driven shield was also used to screen the voltage electrode in some recordings. Currents settled within about 2-2.5 msec in response to a voltage step. For recording synaptic currents, the clamp gain was increased as much as possible without precipitating oscillations and adjusted when necessary during the experiment. However, even with the clamp gain optimally adjusted there was often a small voltage escape during the synaptic response. With the membrane potential clamped at $-80 \mathrm{mV}$, this error did not exceed 2-3 mV and no correction was made for it.

Analysis. Voltage and current signals were continually viewed on an oscilloscope and stored for later analysis on magnetic tape (Racal Store 4), the current signal having first been low-pass-filtered between 300 and $600 \mathrm{~Hz}(-3 \mathrm{~dB})$. Analysis was carried out on computer (PDP 11/ 73 ), and currents were digitized, usually at $1024 \mathrm{~Hz}$. Sampling by the computer was initiated by a stimulus trigger pulse recorded on tape during the experiment. Three to four synaptic currents were averaged at each holding potential, the peaks being lined up exactly before averaging to correct for small variations in the synaptic delay. Synaptic current peak amplitudes and decay time constants were measured from the averaged signals, a nonlinear least-squares fitting procedure being used to fit a single exponential or the sum of 2 exponentials to the decay phase. The effects of drugs on synaptic currents recorded from both ganglion preparations were similar, and results have been pooled for presentation.

Solutions and drugs. The recording chamber, $0.5 \mathrm{ml}$ capacity, was continually perfused at $3 \mathrm{ml} / \mathrm{min}$ with a frog Ringer solution containing (in $\mathrm{mM}$ ): $\mathrm{NaCl}, 116.5 ; \mathrm{KCl}, 2.5 ; \mathrm{CaCl}_{2}, 1.8$ or $4.0 ; \mathrm{NaHEPES}, 5 ; \mathrm{pH}$ adjusted to 7.2 with $\mathrm{NaOH}$ and maintained at $20^{\circ} \mathrm{C}$. Increasing the calcium concentration to $4 \mathrm{~mm}$ tended to prolong the duration of cell survival after impalement and was used for about half the recordings. Antagonists were added to the perfusing solution at least 5 min prior to recording and until their effects on synaptic currents reached a steady state.

The following drugs were used: decamethonium iodide (Koch Light), hexamethonium bromide (Sigma), trimetaphan camsylate (Roche), and $(+)$-tubocurarine chloride (Burroughs Wellcome).

Analysis of the site of drug action. In this paper an ACh antagonist is used in the broadest sense to describe a drug that inhibits the action of $\mathrm{ACh}$. ACh antagonists may inhibit the response to ACh by inhibiting its hinding to receptor, an ACh receptor antagonist (Jenkinson, 1960), or by blocking the open channel, an ion channel blocker (Adams, 1976), and these 2 mechanisms have predictable and distinct effects on synaptic currents (see, for example, Colquhoun et al., 1979; Rang, 1982). Open channel block can be represented according to the following simplified kinetic scheme (Adams, 1976; Colquhoun and Hawkes, 1983):

$$
\text { Shut } \underset{\alpha^{\prime}}{\stackrel{\beta^{\prime}}{\rightleftharpoons}} \text { Open } \underset{k_{-B}}{\stackrel{[B] k_{+B}}{\rightleftarrows}} \text { Blocked, }
$$

where $\beta^{\prime}$ is the effective forward rate constant which increases with the concentration of ACh $\left(x_{A}\right) ; 1 / \alpha^{\prime}$ is the apparent mean open lifetime of the channel in the absence of a channel blocker, so $\alpha^{\prime}$ is the apparent rate constant for channel closing from the open state; $[B]$ is the concentration of the blocker; and $k_{+\mathrm{B}}$ and $k_{-\mathrm{B}}$ are, respectively, the association and dissociation rate constants for blocking and unblocking of the open channel by $B$

Strictly, this form is valid provided that the agonist binding reaction (not shown explicitly above) is much faster than the subsequent shut $\leftrightarrow$ open conformation change. This is probably not true, however, for the nicotinic receptor, where a burst of several channel openings, separated by brief shuttings, occurs during a single activation of the channel (Colquhoun and Sakmann, 1981). However, the fast binding assumption will hold as a good approximation even when there are multiple channel openings as long as $1 / \alpha^{\prime}$ is interpreted as the mean length of a single channel activation (the mean burst length; see Ogden and Colquhoun, 1985, Appendix 2 for details). The form of the dependence of $\beta^{\prime}$ on agonist concentration depends on the details of the binding reaction, but it is not critical for the results presented here.

In the absence of a blocker, synaptic current decays are monoexponential and $\alpha^{\prime}$ approximates to the rate constant $\left(k_{c}\right)$ or reciprocal time constant $\left(1 / \tau_{c}\right)$ of synaptic current decays, provided that ACh is not present during the decay (i.e., $\beta^{\prime}=0$ ) and that channel opening occurs synchronously and much faster than channel closing (Magleby and Stevens, $1972 \mathrm{a}, \mathrm{b}$ ). In the presence of a channel blocker, $B$, the synaptic current decay, is predicted to show 2 exponential components, the rate constants $k_{1}$ and $k_{2}$ being, respectively, faster and slower than the control rate constant, $k_{c}$. The faster rate constant, $k_{1}$, will be given approximately by $\left(\alpha^{\prime}+[B] k_{+B}+k_{-B}\right)$ as long as there is a small fraction of channels open $\left(\beta^{\prime} \ll \alpha\right)$, and the 2 observed rate constants are well separated ( $k_{1}$ $\gg k_{2}$ ). If the rate of dissociation of $B$ is slow compared with $k_{1}$ (i.e., $\left.k_{-B} \ll k_{1}\right)$, then $k_{1}-\left(\alpha^{\prime}+[B] k_{+B}\right)$. Thus, $k_{1}$ increases as $[B]$ is increased. When $B$ dissociates from the channel, the channel returns to the open state before finally shutting, and this produces a slow tail, the rate constant for which is denoted $k_{2}$.

On the basis of this simplified kinetic scheme, an open channel blocker will have no effect on ESC amplitudes (in so far as channels are opened synchronously), since the channels must open before the blocker can act, but the blocker will speed the initial rate of synaptic current decay. The effect of many charged channel blockers is also known to be voltage dependent (procaine: Adams, 1976; tubocurarine: Manalis, 1977; hexamethonium: Ascher et al., 1978, 1979), as expected for a binding site within the membrane potential field.

An ACh receptor antagonist, by definition, prevents the binding of $\mathrm{ACh}$ to its receptor and has no direct effect on subsequent processes, such as channel opening or closing. On the basis of the simplified kinetic scheme, which assumes that ACh disappears from the synaptic cleft very rapidly, a receptor antagonist is predicted to reduce the peak ESC amplitude without affecting the rate of decay. This is undoubtedly an oversimplification, since binding of $\mathrm{ACh}$ to receptors is known to be one of the factors controlling the rate at which it is hydrolyzed or diffuses out of the synaptic cleft (Katz and Miledi, 1973; Pennefather and Quastel, 1981). In the absence of anticholinesterase drugs, however, this effect is likely to be small and can, as a first approximation, be neglected.

The criteria outlined above are generally useful for distinguishing between receptor antagonism and ion channel block as a mechanism by which a drug can antagonize the effect of ACh (see Rang, 1982). It should be pointed out, however, that several drugs are known to be both receptor antagonists and channel blockers at the same receptor ion channel complexes (e.g., tubocurarine: Manalis, 1977; Katz and Miledi, 1978; Colquhoun et al., 1979). In addition, the term ACh receptor antagonist is taken to include different forms of receptor block such as competitive and noncompetitive antagonism since this study cannot distinguish these different mechanisms. 
A CONTROL

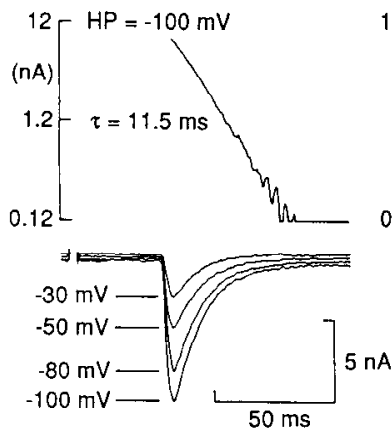

B TUBOCURARINE $1 \mu \mathrm{M}$

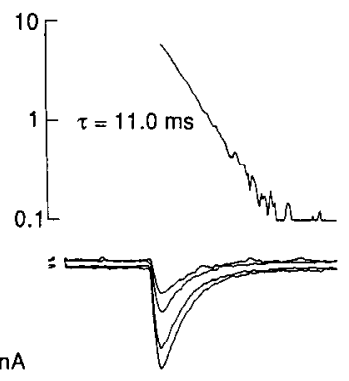

C TUBOCURARINE $3 \mu \mathrm{M}$

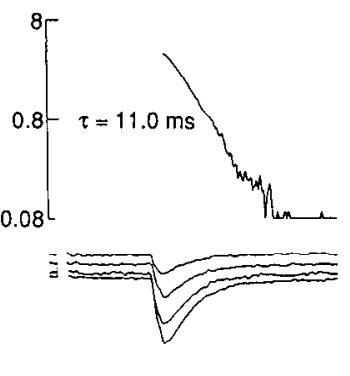

D

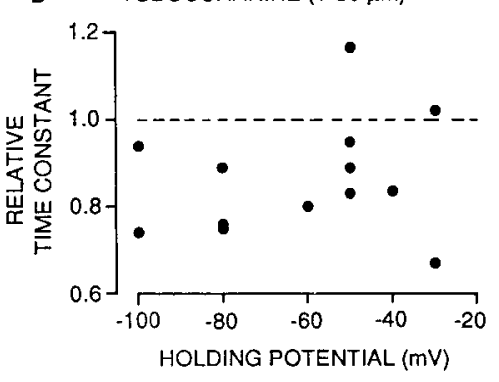

Figure 1. Action of tubocurarine on ESCs recorded from cardiac neurons. ESCs recorded from a cardiac neuron at the indicated holding potentials are shown superimposed in $A$ and in the presence of $1 \mu \mathrm{M}(B)$ and $3 \mu \mathrm{M}(C)$ tubocurarine. Tubocurarine reversibly reduced the peak current amplitude similarly at all potentials. Decays of synaptic currents recorded at $-100 \mathrm{mV}$ are plotted on a semilogarithmic scale together with values of the fitted time constants to show that the decay kinetics are unaffected by tubocurarine. In $D$ the effect of tubocurarine (1-30 $\mu \mathrm{M})$ on decay time constants is shown at different holding potentials. Each point represents a measurement from an individual neuron from a total of 5 neurons. Values shown are expressed relative to control, indicated by the dashed line (1.0). The average reduction in $\tau_{\text {decay }}$ induced by tubocurarine was 9 $\pm 7 \%$ (5 cells).

\section{Results}

In the absence of ACh antagonists ESCs of cardiac and sympathetic ganglia decayed with a single exponential component as described in sympathetic and cardiac ganglia of the bullfrog (Kuba and Nishi, 1979; MacDermott et al., 1980; Connor and Parsons, 1983). The average time constant fitted to ESC decays of cardiac ganglia at $-80 \mathrm{mV}$ was $9.5 \pm 0.7 \mathrm{msec}(n=16)$, a value rather longer than that measured from bullfrog ganglia (6-7 msec at $-80 \mathrm{mV}$, value extrapolated from authors' value of $\tau$ at $-50 \mathrm{mV}$ and their estimate of $H$; Connor and Parsons, 1983). The mean ESC amplitude measured from frog cardiac ganglia at $-50 \mathrm{mV}$ was $-4.9 \pm 0.5 \mathrm{nA}$, which is very similar to that measured in bullfrog cardiac ganglia $(-4.3 \mathrm{nA}$ at -50 $\mathrm{mV}$; Connor and Parsons, 1983).

Recordings from frog sympathetic ganglia were mainly obtained in solution containing $4 \mathrm{~mm}$ calcium (see Materials and Mcthods). Raising the cxtcrnal calcium concentration increased the time constant of ESC decays and also the peak amplitude. The average $\tau$ of ESC decays in $1.8 \mathrm{~mm}$ calcium was $5.3 \pm 0.2$ $(n=2)$ at $-50 \mathrm{mV}$ and a peak amplitude of $-8 \pm 3 \mathrm{nA}(n=$ 2 ), in good agreement with those values measured from bullfrog ganglia under the same conditions $(\tau=5-6 \mathrm{msec}$; Kuba and Nishi, 1979; MacDermott et al., 1980; Connor and Parsons, 1983). The average $\tau$ of ESC decays in 4 mm external calcium was increased to $8.2 \pm 0.6 \mathrm{msec}(n=7)$ at $-50 \mathrm{mV}$ and the peak amplitude was $-15 \pm 3 \mathrm{nA}(n=7)$, in good agreement with those values measured in bullfrog ganglia in similar conditions ( $7 \mathrm{msec},-14 \mathrm{nA}$; Connor et al., 1985).

Increasing external calcium also prolongs the decay of both evoked and miniature synaptic currents in rat submandibular ganglia (Rang, 1981) as well as miniature end-plate currents (Cohen and Van der Kloot, 1978). The increased size of synaptic currents observed in high calcium is likely to be the result of increased transmitter release. The prolongation of the synaptic current decay induced by raising calcium may be explained by a direct effect on channel open time since calcium has been found to increase the mean burst length at the frog end-plate (Colquhoun \& Sakmann, 1985).

ESC peak amplitudes increased, as expected, with membrane potential hyperpolarization, the extrapolated reversal potential for ESCs being -4 and $-8 \mathrm{mV}$ in cardiac and sympathetic ganglia, respectively. The decay time constants of ESCs $\left(\tau_{\text {decay }}\right)$ increased slightly with hyperpolarization, the voltage change corresponding to an $e$-fold change in $\tau_{\text {decay }}$, being $-417 \pm 60$ $\mathrm{mV}(n=16)$ and $-304 \pm 18 \mathrm{mV}(n=14)$ in cardiac and sympathetic ganglia, respectively.

Figure 1 shows a series of ESCs of a cardiac neuron recorded in the absence and presence of 1 and $3 \mu \mathrm{M}$ tubocurarine. In the presence of tubocurarine $(1-30 \mu \mathrm{M})$, synaptic current amplitudes were reduced and $\tau_{\text {decay }}$ only very slightly shortened. At $3 \mu \mathrm{M}$ the peak amplitude of currents was reduced by $54 \pm 3 \%$ (4 cardiac neurons) at all potentials. $\tau_{\text {decay }}$, in contrast, was reduced by only $9 \pm 7 \%$ ( 5 cardiac neurons) in the presence of between 1 and $30 \mu \mathrm{M}$ tubocurarine. Figure $1 D$ shows that the small reduction of $\tau_{\text {decay }}$ induced by tubocurarine was independent of potential.

Figure 2 shows the effect of 10,30 , and $600 \mu \mathrm{M}$ hexamethonium on ESCs recorded from a sympathetic neuron. Hexamethonium in concentrations of up to $100 \mu \mathrm{M}$ had no effect on either ESC amplitude or $\tau_{\text {decay }}$ ( 6 cells: 3 cardiac, 3 sympathetic): In the presence of $10 \mu \mathrm{M}$ hexamethonium the average peak amplitude was $101 \pm 0.3 \%$ and $\tau_{\text {decay }}$ was $99 \pm 0.7 \%$ of control values ( 3 cells). At concentrations greater than $100 \mu \mathrm{M}$ hexamethonium reduced ESC peak amplitudes, but even at $600 \mu \mathrm{M}$ there was only a $40 \%$ reduction with no marked effect on decay kinetics (Fig. 2). The average $\tau_{\text {decay }}$ measured from ESCs in the presence of between 10 and $600 \mu \mathrm{M}$ hexamethonium was $94 \pm$ $2 \%$ of control values ( 6 cells).

Trimetaphan reduced ESC amplitude, and, at a higher concentration, it also affected the decay kinetics ( 5 cells: 4 cardiac, 1 sympathetic). In the presence of 3-100 $\mu \mathrm{M}$ trimetaphan, ESC amplitudes were reduced, there being approximately $50 \%$ inhibition at $10 \mu \mathrm{M}$. In the presence of $100 \mu \mathrm{M}$ trimetaphan, current decays were split into 2 components and the time constants of these were voltage dependent. At $-80 \mathrm{mV} \tau_{\text {decay }}$ of the fast component was reduced by $40 \%$ relative to control, whereas at $-50 \mathrm{mV}$ there was only a $12 \%$ reduction. The inhibition of ESC amplitude produced by $100 \mu \mathrm{M}$ trimetaphan was also voltage dependent, with reductions of 81 and $58 \%$ at -80 and -50 $\mathrm{mV}$, respectively.

Figure 3 highlights the different effects of tubocurarine, hexamethonium, and trimetaphan on ESCs of frog ganglia and on ESCs of the rat submandibular ganglion (Rang, 1982). Control 


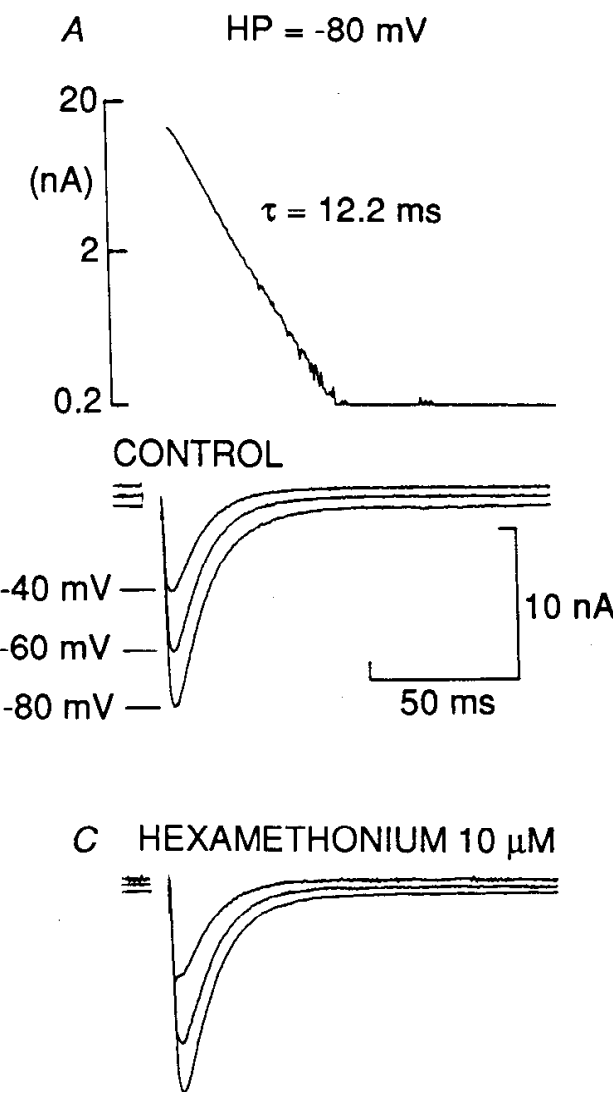

$$
\text { B } \quad \mathrm{HP}=-80 \mathrm{mV}
$$
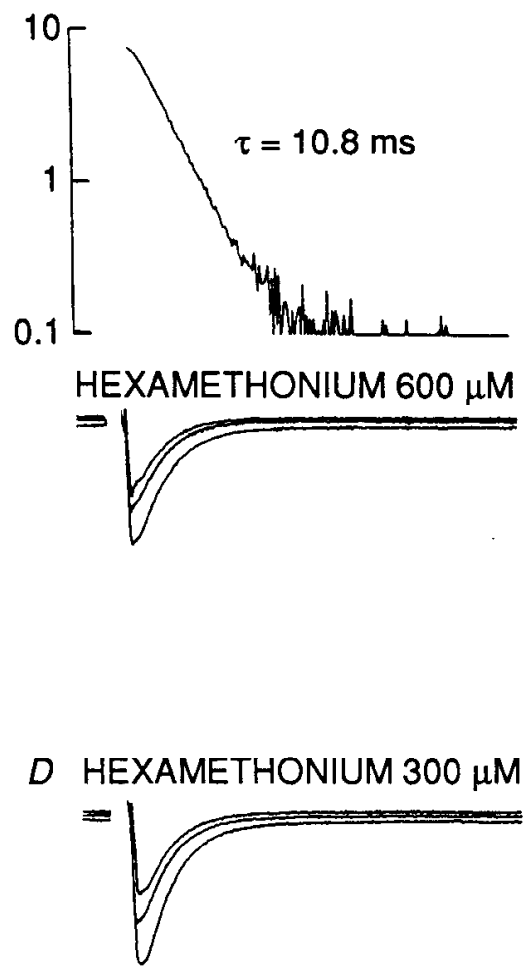

Figure 2. Action of hexamethonium on ESCs recorded from a sympathetic neuron. Control ESCs $(A)$ and those in the presence of $10 \mu \mathrm{M}(C), 300 \mu \mathrm{M}(D)$, and $600 \mu \mathrm{M}(B)$ hexamethonium at the indicated potentials. At $10 \mu \mathrm{M}$, hexamethonium did not effect the synaptic response, whereas at 300 and $600 \mu \mathrm{M}$ it reduced the peak amplitude. The semilogarithmic plot of the decay of synaptic currents at $-80 \mathrm{mV}$ and values of the fitted time constants show that the decay kinetics are unaffected by hexamethonium.
ESCs of rat submandibular ganglia are described by 2 exponentials corresponding to "fast" and "slow" ACh-activated synaptic channels (Rang, 1981). In Figure 3 the effects of the drugs on the "fast" component of the rat ESCs are compared with the frog because of the similar time constants. However, the effects of the drugs on the "fast" component shown in Figure 3 are very similar to those on the "slow" component (Rang, 1982). Whereas in the frog ganglia tubocurarine (1-30 $\mu \mathrm{M}$ ) reduced ESC amplitudes in a dose-dependent manner, effects on rat ganglionic current amplitudes were only observed at concentrations exceeding $20 \mu \mathrm{M}$. In the rat ganglion, tubocurarine acts predominantly as an ion channel blocker of the "slow" channels at these concentrations, speeding the decay of the "slow" component with little effect on the peak amplitude. Hexamethonium had no effect on the decay kinetics of ESCs recorded from frog ganglia (up to $600 \mu \mathrm{M}$ ), whereas it is a potent channel blocker in rat ganglia, speeding the initial rate of decay of synaptic currents affecting both the "fast" and "slow" components of the decay. $\tau_{\text {decay }}$ of ESCs of rat ganglia was reduced by $\approx 50 \%$ in the presence of $10 \mu \mathrm{M}$ hexamethonium (Rang, 1982). Trimetaphan reduced the peak current amplitudes in both the frog and rat ganglion preparations but was effective at slightly lower concentrations in the rat.

The effects of decamethonium were also studied. Figure 4 shows the action of $100 \mu \mathrm{M}$ decamethonium on synaptic currents recorded from a cardiac neuron. Decamethonium (10-100 $\mu \mathrm{M})$ consistently split the decay of ESCs, recorded at potentials more negative than about $-50 \mathrm{mV}$, into 2 components with decay rates, respectively, faster and slower than control. Table 1 shows that the reduction in $\tau_{\text {decay }}$ is concentration and voltage dependent; the initial rate of decay increases as the concentration of decamethonium is increased, and the effects are more pronounced at $-80 \mathrm{mV}$ than at $-40 \mathrm{mV}$. These results are consistent with decamethonium being an ion channel blocker, as has been shown in the rat submandibular ganglion (Gurney and Rang, 1984), and at the neuromuscular junction (Adams and Sakmann, 1978; Milne and Byrne, 1981). The slow component of ESC decays did not vary with decamethonium concentration as expected for open channel block (see Colquhoun and Hawkes, 1983). A similar result was obtained by Adams and Sakmann (1978) at the frog end-plate, the slow component only decreasing

\begin{tabular}{|c|c|c|c|c|c|}
\hline $\begin{array}{l}\text { Drug } \\
(\mu \mathrm{M})\end{array}$ & $n$ & $\tau_{\text {control }}$ & $\tau_{\text {fast }}$ & $\tau_{\text {slow }}$ & $A_{\mathrm{dec}} / A_{\mathrm{con}}$ \\
\hline \multicolumn{6}{|c|}{$-80 \mathrm{mV}$} \\
\hline 10 & 3 & $7.9 \pm 0.7$ & $6.8 \pm 0.7$ & $21.2 \pm 0.4$ & $0.99 \pm 0.06$ \\
\hline 30 & 5 & $8.6 \pm 0.6$ & $5.9 \pm 0.7$ & $18.7 \pm 1.7$ & $0.88 \pm 0.06$ \\
\hline 100 & 2 & $8.7 \pm 1.2$ & $1.7 \pm 0.1$ & $23.4 \pm 6.7$ & $0.31 \pm 0.06$ \\
\hline \multicolumn{6}{|c|}{$-40 \mathrm{mV}$} \\
\hline 10 & 4 & $8.2 \pm 0.5$ & $9.9 \pm 1.0$ & - & $0.92 \pm 0.08$ \\
\hline 30 & 7 & $8.1 \pm 0.6$ & $11.5+1.0$ & - & $0.79 \pm 0.07$ \\
\hline 100 & 2 & $7.9 \pm 1.0$ & $4.0 \pm 1.7$ & $18.7 \pm 1.9$ & $0.27 \pm 0.09$ \\
\hline
\end{tabular}

Average data on the effect of 10,30 , and $100 \mu \mathrm{M}$ decamethonium on ESC decay time constants and peak current amplitudes at -80 and $-40 \mathrm{mV}$. Control ESC decays $\left(\tau_{\text {control }}\right)$ are compared with those in the presence of decamethonium $\left(\tau_{\text {fas }}\right.$ and $\left.\tau_{\text {slow }}\right)$. The peak current amplitude in the presence of decamethonium is expressed as a fraction of the control value $\left(A_{\mathrm{dec}} / A_{\text {con }}\right)$. Values are means \pm SE calculated from $n$ number of cells. 

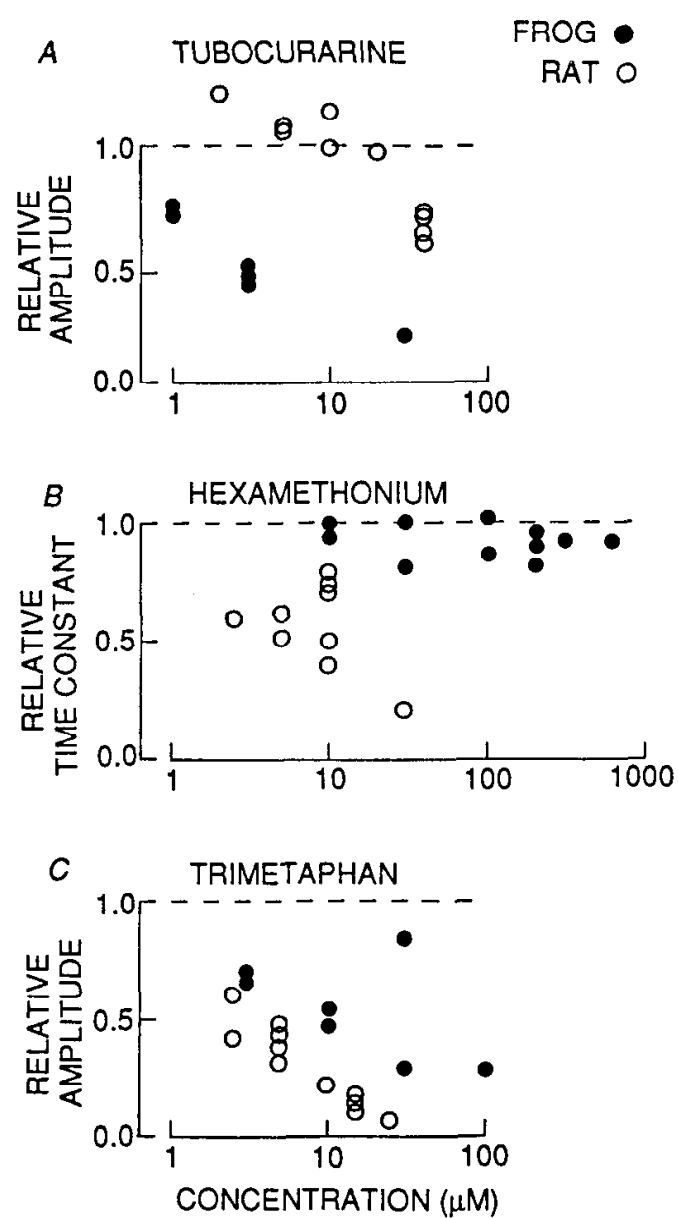

Figure 3. ACh antagonist actions on synaptic currents of frog sympathetic and cardiac ganglia compared with those of the rat submandibular ganglion. The actions of tubocurarine $(A)$, hexamethonium $(B)$, and trimetaphan $(C)$ are compared. The plotted points represent responses from separate cells $\left(-80 \mathrm{mV} ; 20^{\circ} \mathrm{C}\right)$. The actions of each of the 3 drugs were tested on at least 5 different frog neurons. Data on the rat ganglia are reproduced from Rang (1982). Effects on rat ESC decays are shown for the "fast" component, though similar results are obtained for these actions on the "slow" component; control ESC decays of submandibular ganglionic currents are biexponential (Rang, 1981). The reduction in either peak amplitude or $\tau_{\text {decay }}$ induced by the antagonists is shown relative to the control values (indicated by the broken line).

significantly with decamethonium concentrations at much more negative potentials $(-130 \mathrm{mV})$. Table 1 also shows that 10 and $30 \mu \mathrm{M}$ decamethonium had little effect on the peak synaptic current amplitude; however, at $100 \mu \mathrm{M}$ peak amplitudes were reduced to $27 \pm 9$ and $31 \pm 6 \%$ at -40 and $-80 \mathrm{mV}$, respectively. The reduction in the peak amplitude of ESCs indicates that at this concentration $(100 \mu \mathrm{M})$ decamethonium may be an $\mathrm{ACh}$ receptor antagonist as well as a channel blocker. Alternatively, a channel blocker would reduce the peak amplitude of ESCs if channel opening was not synchronous (see appendix to Rang, 1982).

\section{Discussion}

The results demonstrate the presence of a neuronal receptor in frog distinct from that described in mammalian ganglia. The actions of ACh antagonists at frog ganglia-in particular, tubocurarine and hexamethonium - were very unlike their reported effects in the rat submandibular ganglion and similar to their effects at the neuromuscular junction (see Table 2 for summary and references).

In frog ganglia, tubocurarine and, in higher concentrations, hexamethonium reduced the amplitude of synaptic currents to a degree that was independent of membrane potential and had no appreciable effect on $\tau_{\text {decay }}$, results consistent with these drugs acting as receptor antagonists. Similar effects of these drugs are observed at the neuromuscular junction, where tubocurarine reduces end-plate current amplitude at concentrations similar to those effective at the frog ganglia (Colquhoun et al., 1979; Shaker et al., 1982), and near millimolar concentrations of hexamethonium are required to produce an equivalent inhibition (Milne and Byrne, 1981). Inhibition of end-plate currents induced by hexamethonium and tubocurarine is independent of membrane potential unless the fibers are strongly hyperpolarized, when the additional channel-blocking effect becomes noticeable. In contrast, in the rat ganglion these drugs predominantly act as ion channel blockers, their effects being highly voltage-dependent and accompanied by a marked speeding of current decays at hyperpolarized potentials (Rang, 1982).

The small but consistent reduction of $\tau_{\text {decay }}$ induced by tubocurarine in frog ganglia was unlikely to be the result of channel block since the effect was independent of voltage. Tubocurarine also has a similar effect on $\tau_{\text {dccay }}$ of end-plate currents (Colquhoun et al., 1977; Feltz et al., 1977), and here it was suggested that if the rate of ACh removal during the decay of end-plate currents was rate limiting under these conditions tubocurarine (or any ACh receptor antagonist) by reducing the number of available binding sites for ACh would speed the removal of ACh from the synaptic cleft and thus speed the rate of synaptic current decay (see also Katz and Miledi, 1973). A similar explanation could account for the action of tubocurarine in the frog ganglia, if it is assumed that the decay rate of synaptic currents is not solely determined by the rate of channel closing.

Decamethonium was found to be an ion channel blocker in frog ganglia, similar to its effects at the end-plate (Adams and Sakmann, 1978) and the rat submandibular ganglion (Ascher et al., 1979; Gurney and Rang, 1984). At the end-plate, decamethonium is an agonist (Adams and Sakmann, 1978), but it is not an agonist in mammalian ganglia (Paton and Perry, 1953; Ascher et al., 1979; Gurney and Rang, 1984). If the frog neuronal receptor is like that of skeletal muscle, decamethonium should also be an agonist at this site. Although in the present study no agonist action of decamethonium was apparent, patch-clamp recordings from freshly dissociated frog sympathetic neurons (Lipscombe, 1986a, b) have shown that decamethonium is an agonist, inducing channel openings similar to those seen at the end-plate. The actions of decamethonium are therefore consistent with the generalization that the neuronal nicotinic receptor of frog ganglia resembles that of skeletal muscle.

Although the present results suggest that the neuronal receptor of the frog is qualitatively similar to the end-plate receptor, the following observations establish that they are not identical.

1 . The effect of $\alpha$-BuTx. Marshall (1981) found that $\alpha$-BuTx did not totally abolish the synaptic response, its effect was slowly reversible, and rather higher concentrations than those effective at the end-plate were required for inhibition.

2. The channel open times are different. The time course of synaptic currents in frog ganglia (Kuba and Nishi, 1979; MacDermott et al., 1980; Lipscombe, 1986a, b) are about 5 times slower than those at the end-plate (Magleby and Steven, 1972b). This suggests that the channel open time of the neuronal 
$A$

CONTROL
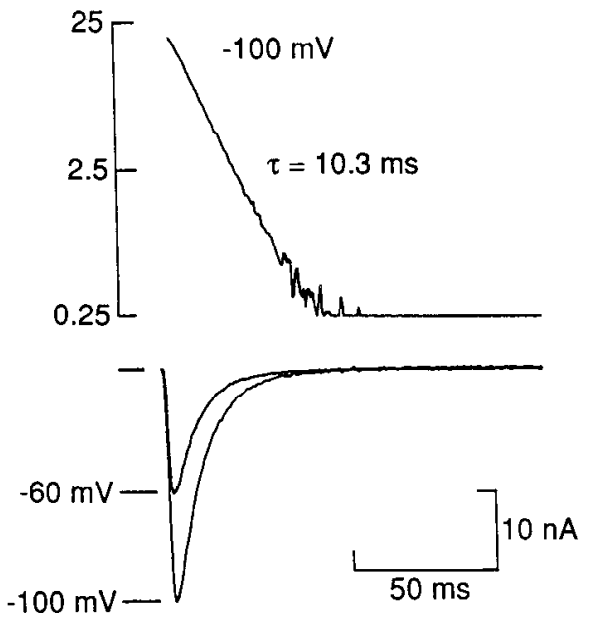

B DECAMETHONIUM $100 \mu \mathrm{M}$
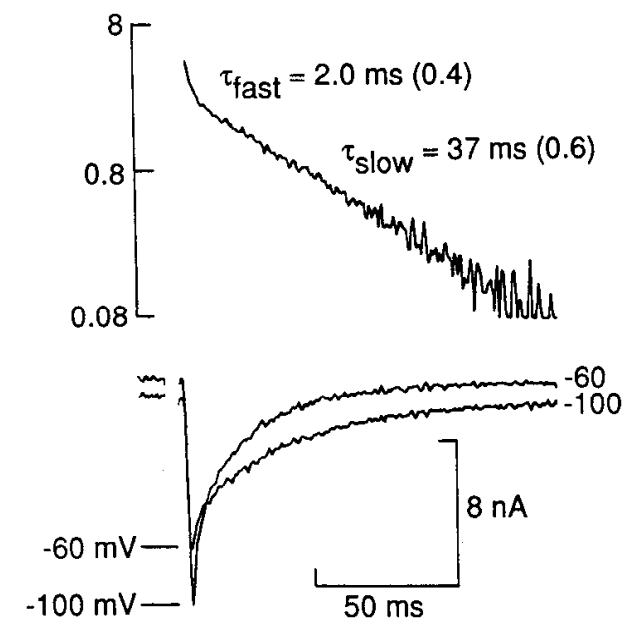

Figure 4. Action of decamethonium on ESCs of a sympathetic neuron. Synaptic currents recorded at -60 and $-100 \mathrm{mV}$ in the absence $(A)$ and presence of $100 \mu \mathrm{M}$ decamethonium $(B)$. The semilogarithmic plots of the decay of currents recorded at $-100 \mathrm{mV}$ are shown together with the fitted time constants. In the presence of decamethonium the decay is biexponential. The peak amplitudes of currents are also reduced at this concentration. The effect of decamethonium on both the time course and peak amplitude of the currents is greater at the more hyperpolarized potential of $-100 \mathrm{mV}$. receptor is longer. This has been confirmed from patch-clamp recordings from frog sympathetic neurons (Lipscombe, 1986a, b).

3. Voltage dependence of synaptic current decays. The voltage dependence of the time constant of end-plate current decays is more pronounced than that measured in frog ganglia. At 20 $25^{\circ} \mathrm{C}$, about $100 \mathrm{mV}$ hyperpolarization is required to produce an $e$-fold increase in $\tau$ at the end-plate (Magleby and Stevens, 1972a) compared with estimates of -150 to $-500 \mathrm{mV}$ required to produce a similar increase in $\tau$ at frog and bullfrog ganglia (frog: present study; bullfrog: Kuba and Nishi, 1979; MacDermott et al., 1980; Connor and Parsons, 1983).

4. The size of synaptic currents. The amplitude of the synaptic response of ganglia is about 20 times smaller than end-plate currents. This could be the result of less ACh release during a synaptic event or a lower density of postsynaptic nicotinic receptors in the ganglia compared with the end-plate. Alternatively, the smaller synaptic response may reflect a lower intrinsic sensitivity of the neuronal receptor for ACh or that the neuronal channel has a smaller single-channel conductance. The single- channel conductance of the frog neuronal channel is smaller, 18 pS (Lipscombe, 1986a, b; also scc Marshall, 1985), than the end-plate, $30 \mathrm{pS}$ (Colquhoun and Sakmann, 1981); however, this does not account for the large difference in the size of synaptic currents. The sensitivity of the neuronal receptor for $\mathrm{ACh}$ has not been measured and therefore remains as another possible difference between neuronal and skeletal muscle receptors.

In conclusion, we have shown that the neuronal nicotinic receptor responsible for mediating fast excitatory transmission in the cardiac and sympathetic ganglia of the frog is similar in its pharmacological characteristics to that found at the endplate. This neuronal nicotinic receptor is not the same as that so far studied in mammalian ganglia; both the $\mathrm{ACh}$ receptor antagonist binding site and ion channel blocker binding site are different for the 2 receptors. Although similar, the frog neuronal ACh receptor channel is not identical to that found at the endplate, having quite distinct channel gating kinetics. An important consideration is whether this type of receptor is of functional importance only in the nervous system of the frog. There is an abundance of evidence for the presence of high-affinity binding

Table 2. Relative potencies of $\mathrm{ACh}$ antagonists on the rat submandibular ganglion ("fast" and "slow" components), frog cardiac, and sympathetic ganglia, and frog and rat neuromuscular junction

\begin{tabular}{|c|c|c|c|c|c|c|}
\hline \multirow{2}{*}{$\begin{array}{l}\text { Drug } \\
(\mu \mathrm{M})\end{array}$} & \multicolumn{2}{|c|}{ Rat ganglion } & \multicolumn{2}{|c|}{ Frog ganglia } & \multicolumn{2}{|c|}{$\begin{array}{l}\text { Frog/rat }{ }^{d} \\
\text { muscle }\end{array}$} \\
\hline & AMP & $\tau$ & AMP & $\tau$ & $\overline{\mathrm{AMP}}$ & $\tau$ \\
\hline Tubocurarine & $>40$ & $>20^{b}$ & $\approx 3$ & $>30$ & $\approx 1$ & $>3^{e f f}$ \\
\hline Hexamethonium & $>20^{u}$ & $\approx 10^{b}$ & $300-600$ & $>600$ & $>1000$ & $\approx 1000^{g}$ \\
\hline Decamethonium & $>20$ & $10^{c}$ & $\approx 100$ & $30-100$ & $>100$ & $25-50^{g \cdot h}$ \\
\hline Trimetaphan & $\approx 5$ & $\approx 15^{b}$ & $\approx 109$ & 100 & 100 & $25^{d}$ \\
\hline
\end{tabular}

Concentrations (in $\mu \mathrm{M}$ ) of drugs producing a $50 \%$ reduction in peak amplitude of synaptic currents, Amp, and a $50 \%$ reduction in decay time constants, $\tau$, are shown. Data for responses at $-80 \mathrm{mV}$ and $20^{\circ} \mathrm{C}$ were used where possible. $>$, Indicates that higher concentrations were not used, and the value given represents a lower limit.

${ }^{a}$ This value is much higher if single responses are used; inhibition of peak current amplitude by hexamethonium is highly use-dependent (Gurney and Rang, 1984).

${ }^{b}$ Rang, 1982.

c Gurney and Rang, 1984.

"Gibb and Marshall, 1984.

- Colquhoun et al., 1979.

Shaker et al., 1982.

${ }^{8}$ Milne and Byrne, 1981.

${ }^{h}$ Adams and Sakmann, 1978. 
sites for $\alpha$-BuTx in the mammalian brain, but their function remains unclear (see Clarke et al., 1985). There are also indications from molecular biological studies that the mammalian brain possesses different types of nicotinic receptor since cDNAs encoding for different $\alpha$-subunits of the neuronal nicotinic receptor have now been isolated. Further studies are necessary, however, to determine whether a class of neuronal nicotinic receptor like that found in frog ganglia is of physiological importance in the mammalian nervous system.

\section{References}

Adams, P. R. (1976) Drug blockade of open end-plate channels. J. Physiol. (Lond.) 260: 531-552.

Adams, P. R., and B. Sakmann (1978) Decamethonium both opens and blocks endplate channels. Proc. Natl. Acad. Sci. USA 75: 29942998.

Ascher, P., A. Marty, and T. O. Neild (1978) The mode of action of antagonists of the excitatory response to acetylcholine in Aplysia neurones. J. Physiol. (Lond.) 278: 207-235.

Ascher, P., W. A. Large, and H. P. Rang (1979) Studies on the mechanism of action of acetylcholine antagonists on rat parasympathetic ganglion cells. J. Physiol. (Lond.) 295: 139-170.

Boulter, J., K. Evans, D. Goldman, G. Martin, D. Treco, S. Heinemann, and J. Patrick (1986) Isolation of a cDNA clone for a possible neural nicotinic acetylcholine receptor $\alpha$-subunit. Nature 319: 368-374.

Brown, D. A., and L. Fumagalli (1977) Dissociation of alpha-bungarotoxin binding and receptor block in the rat superior cervical ganglion of the rat. Brain Res. 129: 165-168.

Bursztajn, S., and M. D. Gershon (1977) Discrimination between nicotinic receptors in vertebrate ganglia and skeletal muscle by alphabungarotoxin and cobra venoms. J. Physiol. (Lond.) 269: 17-31.

Chiappinelli, V. A., and R. E. Zigmond (1978) $\alpha$-Bungarotoxin blocks nicotinic transmission in the avian ciliary ganglion. Proc. Natl. Acad. Sci. USA 75: 2999-3003.

Clarke, P. B. S., R. D. Schwartz, S. M. Paul, C. B. Pert, and A. Pert (1985) Nicotinic binding in rat brain: Autoradiographic comparison of [ $\left.{ }^{3} \mathrm{H}\right]$ acetylcholine, $\left[{ }^{3} \mathrm{H}\right]$ nicotine, and $\left[{ }^{125} \mathrm{I}\right]-\alpha$-bungarotoxin. J. Neurosci. 5: 1307-1315.

Cohen, I., and W. Van der Kloot (1978) Effects of $\left[\mathrm{Ca}^{2+}\right]$ and $\left[\mathrm{Mg}^{2+}\right]$ on the decay of miniature endplate currents. Nature 271:77-79.

Colquhoun, D. (1981) The kinetics of conductance changes at nicotinic receptors of the muscle end-plate and of ganglia. In Drug Receptors and Their Effectors. N. Birdsall, cd., pp. 107-127, Macmillan Press, London.

Colquhoun, D., and A. G. Hawkes (1983) The principles of the stochastic interpretation of ion-channel mechanisms. In Single-Channel Recording, B. Sakmann and E. Neher, eds., p. 135, Plenum, New York.

Colquhoun, D., and B. Sakmann (1981) Fluctuations in the microsecond time range of the current through single acetylcholine receptor ion channels. Nature 294: 464-466.

Colquhoun, D., and B. Sakmann (1985) Fast events in single-channel currents activated by acetylcholine and its analogues at the frog muscle end-plate. J. Physiol. (Lond.) 369: 501-557.

Colquhoun, D., W. A. Large, and H. P. Rang (1977) An analysis of the action of a false transmitter at the neuromuscular junction. $J$. Physiol. (Lond). 266: 361-395.

Colquhoun, D., F. Dreyer, and R. E. Sheridan (1979) The actions of tubocurarine at the frog neuromuscular junction. J. Physiol. (Lond.) 293: 247-284.

Connor, E. A., and R. L. Parsons (1983) Analysis of fast excitatory postsynaptic currents in bullfrog parasympathetic ganglion cells. $J$. Neurosci. 3: 2164-2171.

Connor, E. A., S. M. Neel, and R. L. Parsons (1985) Influence of the extracellular ionic environment on ganglionic fast excitatory postsynaptic currents. Brain Res. 339: 227-235.

Feltz, A., W. A. Large, and A. Trautmann (1977) Analysis of atropine action at the frog neuromuscular junction. J. Physiol. (Lond.) 269: 109-130.

Freeman, J. A. (1977) Possible regulatory function of acetylcholine in maintenance of retinotectal synapses. Nature 269: 218-222.

Freeman, J. A., J. T. Schmidt, and R. E. Oswald (1980) Effect of $\alpha$-bungarotoxin on retinotectal synaptic transmission in the goldfish and the toad. Neuroscience 5: 929-942.

Gibb, A. J., and I. G. Marshall (1984) Pre- and post junctional effects of tubocurarine and other nicotinic antagonists during repetitive stimulation in the rat. J. Physiol. (Lond.) 351: 275-297.

Goldman, D., E. Deneris, W. Luyten, A. Kochhar, J. Patrick, and S. Heinemann (1987) Members of a nicotinic acetylcholine receptor gene family are expressed in different regions of the mammalian central nervous system. Cell 48: 965-973.

Gurney, A. M., and H. P. Rang (1984) The channel-blocking action of methonium compounds on rat submandibular ganglion cells. $\mathrm{Br}$. J. Pharmacol. 82: 623-642.

Jenkinson, D. H. (1960) The antagonism between tubocurarine and substances which depolarise the motor end-plate. J. Physiol. (Lond.) 152: 309-324.

Katz, B., and R. Miledi (1973) The binding of acetylcholine to receptors and its removal from the synaptic cleft. J. Physiol. (Lond.) 231: 549-574.

Katz, B., and R. Miledi (1978) A re-examination of curare action at the motor end-plate. Proc. R. Soc. London [Biol.] 203: 119-133.

Kuba, K., and S. Nishi (1979) Characteristics of fast excitatory postsynaptic current in bullfrog sympathetic ganglion cells. Pfluegers Arch. 378: 205-212.

Lee, C. Y., S. L. Chang, S. T. Kau, and Shing-Hui Luh (1972) Chromatographic separation of the venom of Bungarus multicinctus and characterisation of its components. J. Chromatogr. 72: 61-70.

Lee, G. M., and S. Nishi (1972) Analysis of the mechanism of action of some ganglion-blocking drugs in the rabbit superior cervical ganglion. Br. J. Pharmacol. 46: 78-88.

Libet, B., S. Chichibu, and T. Tosaka (1968) Slow synaptic responses and excitability in sympathetic ganglia of the bullfrog. J. Neurophysiol. 31 : 383-395.

Lipscombe, D. (1986a) Pharmacology of nicotinic receptors in frog neurones: Electrophysiological studies on intact and dissociated ganglia. Ph.D. thesis, University of London.

Lipscombe, D. (1986b) Properties of ACh receptor channels in adult frog sympathetic neurons: Patch clamp studies. Soc. Neurosci. Abstr. 12: $14 a$.

Lipscombe, D., and H. P. Rang (1984) Acetylcholine antagonists in frog cardiac ganglion cells. IUPHAR 9th Int. Cong. Pharmacol., 617a.

MacDermott, A. B., E. A. Connor, V. E. Dionne, and R. L. Parsons (1980) Voltage clamp study of fast excitatory synaptic currents in bullfrog sympathetic ganglion cells. J. Gen. Physiol. 75: 39-60.

Magleby, K. L., and C. F. Stevens (1972a) The effect of voltage on the time course of end-plate currents. J. Physiol. (Lond.) 233: 151171.

Magleby, K. L., and C. F. Stevens (1972b) A quantitative description of end-plate currents. J. Physiol. (Lond.) 233: 173-197.

Manalis, R. S. (1977) Voltage-dependent effect of curare at the frog neuromuscular junction. Nature 267: 366-368.

Marshall, L. M. (1981) Synaptic localization of $\alpha$-bungarotoxin binding which blocks nicotinic transmission at frog sympathetic neurons. Proc. Natl. Acad. Sci. USA 78: 1948-1952.

Marshall, L. M. (1985) Presynaptic control of synaptic channel kinetics in sympathetic neurones. Nature 317: 621-623.

McMahan, U. J., and S. W. Kuffler (1971) Visual identification of synaptic boutons on living ganglion cells and of varicosities in postganglionic axons in the heart of the frog. Proc. R. Soc. London [Biol.] 177: 485-508.

Miledi, R., and L. T. Potter (1971) Acctylcholine receptors in muscle fibres. Nature 233: 599-603.

Milne, R. J., and J. H. Byrne (1981) Effects of hexamethonium and decamethonium on end-plate current parameters. Mol. Pharmacol. 19: 276-281.

Nishi, S., and K. Koketsu (1960) Electrical properties and activities of single sympathetic neurones on frogs. J. Cell. Comp. Physiol. 55: $15-30$.

Ogden, D. C., and D. Colquhoun (1985) Ion channel block by acetylcholine, carbachol and suberyldicholine at the frog neuromuscular junction. Proc. R. Soc. London [Biol.] 225: 329-355.

Paton, W. D. M., and W. L. M. Perry (1953) The relationship between depolarisation and block in the cat's superior cervical ganglion. J. Physiol. (Lond.) 119: 43-57.

Paton, W. D. M., and E. J. Zaimis (1951) Paralysis of autonomic ganglia by methonium salts. Br. J. Pharmacol. 6: 155-168. 
Pennefather, P. and D. M. J. Quastel (1981) Relation between subsynaptic receptor blockade and response to quantal transmitter at the mouse neuromuscular junction. J. Gen. Physiol. 78: 313-344.

Rang, H. P. (1981) The characteristics of synaptic currents and responses to acetylcholine of rat submandibular ganglion cells. J. Physiol. (Lond.) 311: 23-55.

Rang, H. P. (1982) The action of ganglionic blocking drugs on the synaptic responses of rat submandibular ganglion cells. Br. J. Pharmacol. 75: 151-168.

Ravdin, P. M., and D. K. Berg (1979) Inhibition of neuronal acetylcholine sensitivity by $\alpha$-toxins from Bungarus multicinctus venom Proc. Natl. Acad. Sci. USA 76: 2072-2076.
Shaker, N., A. T. Eldefrawi, L. G. Aguayo, J. E. Warnick. E. X. Albuquerque, and M. E. Eldefrawi (1982) Interactions of d-tubocurarine with the nicotinic acetylcholine receptor/channel molecule. J. Pharmacol. Exp. Ther. 220: 172-177.

Skok, V. I. (1965) Conduction in tenth ganglion of the frog sympathetic trunk. Fed. Proc. Trans. Suppl. 24: T363-367.

Skok, V. I. (1986) Channel blocking mechanism ensures specific blockade of synaptic transmission. Neuroscience 17: 1-9.

Skok, V. I., A. A. Selyanko, and V. A. Derkach (1983) Channel blocking activity is a possible mechanism for selective ganglion blockade. Pfluegers Arch. 398: 169-171. 